\title{
Experimental determination of wind action on triangular solar panel assemblies
}

\author{
Olga Hubova ${ }^{1, *}$, Michal Franek ${ }^{2}$ and Marek Macak $^{3}$ \\ ${ }^{1}$ Slovak University of Technology, Department of Structural Mechanics, 81005 Bratislava, Slovak \\ Republic \\ ${ }^{2}$ Slovak University of Technology, Department of Building Construction, 81005 Bratislava, Slovak \\ Republic \\ ${ }^{3}$ Slovak University of Technology, Department of Mathematics, 81005 Bratislava, Slovak Republic
}

\begin{abstract}
The article deals with aerodynamic study of solar panel assemblies. Experimental measurements were realized in BLWT wind tunnel. The aim of the solution was to determine the maximum pressure and suction wind load on top and bottom surfaces of panels. The resulting net pressure coefficient represents the maximum local pressure in each panel row as maximum values from all wind directions. The experimentally obtained $c_{p, n e t}$ values were compared with the conservative values in EN 1991-1-4 for open monopitch canopies. A lower wind load in the inner regions of the triangular assemblies should be used in the design of fixing supports.
\end{abstract}

\section{Introduction}

Currently, solar panels are used to utilise alternative energy sources. They are placed on the roofs of buildings but also on the terrain. Because of the shape of the terrain, various geometric panel assemblies are placed on the plots to obtain enough energy from the sun and to use the available lands. Solar panels can form a rectangle, a triangle, and by combining these two, we will get a trapezoidal assembly. The wind load in this case depends on the position of the solar panel within the assembly. EN 1991-1-4 [1] does not include groups of panels or open roofs arranged in rows and exposed to wind, and therefore the values for open roof design are based on the provisions in Table 7.6 in [1]. The overall force coefficients $\mathrm{c}_{\mathrm{f}}$ and net pressure coefficients $c_{p \text {,net }}$ take account of combined effect of wind on upper and lower surfaces of the canopies for all wind directions.

The aim of the experimental measurements of the wind effects on the triangular panel assembly was to obtain the wind load values of the upper and lower surface of the individual panels by measuring in BLWT wind tunnel (Boundary layer wind tunnel).

Since existing standards consider wind loads only for typical object shapes, wind tunnel tests on models allow a better understanding of the wind effects on a particular objects arrangement at a given location and also determine local extreme loads on individual

\footnotetext{
Corresponding author: olga.hubova@ stuba.sk
} 
surfaces. The wind flow in BLWT wind tunnel represents with technical accuracy the wind flow in the lower part of the atmosphere up to about $200 \mathrm{~m}$ above the ground, where the objects are located. BLWT STU tunnel [2] with modeled boundary layer allows repeated measurements for different wind directions and speeds. Wind effect on structurescan be observed in model reduction experimentally, and the most unfavorable effects of wind on the objects can be determined.

\section{Wind load}

Effects and wind loads on structures are given by EN 1991-1-4 and National Annex EN 1991-1-4 / NA. The wind load calculation is based on the specific wind situation in the given area or specific location where the structure is built. The following factors affect the resulting wind load values:

$1 /$ site-specific wind conditions,

2 / roughness of the terrain,

3 / aerodynamic characteristics of the shape of the object.

The wind load belongs into the field of aerodynamics. Peak wind pressures are defined based on long-term meteorological measurements. In terms of wind flow around objects, air can be considered an ideal and incompressible fluid with low resistance, where the effect of friction is limited to the area of obstruction. The character of the wind flow around the objects determines Reynolds number

$$
\operatorname{Re}=d \cdot v / v
$$

where $d$ - is the characteristic size of the obstacle, $v$ - is flow velocity, $v=1.5 \cdot 10^{-5}\left[\mathrm{~m}^{2} / \mathrm{s}\right]$ is kinematic viscosity.

\subsection{Wind velocity and pressure}

The basic characteristics of turbulent wind flow are mean wind velocity, peak velocity pressure and resulting wind pressure at the area.

Mean wind velocity at height $z$ depends on terrain, and reference wind velocity

$$
v_{\mathrm{m}}(z, t)=\frac{1}{T} \int_{0}^{T} v(z, t) d t=v_{\mathrm{m}}(z)=0,19\left(z / z_{0, \mathrm{II}}\right)^{0,07} \ln \left(z / z_{0}\right) \cdot v_{\mathrm{b}}
$$

where $v_{b}$ - is reference wind velocity, $z_{0}$ - roughness length

Peak velocity pressure $q_{\mathrm{p}}(z)$ takes into account turbulence intensity $I_{\mathrm{v}}(z)$

$$
\begin{aligned}
& q_{\mathrm{p}}(z)=\left[1+7 I_{\mathrm{v}}(z)\right] \cdot 1 / 2 \cdot \rho \cdot v_{\mathrm{m}}^{2}(z) \\
& I_{\mathrm{v}}(z)=\frac{k_{I}}{c_{0}(z) \cdot \ln \left(z / z_{0}\right)}
\end{aligned}
$$

The net pressure on roof is the difference between the pressures on the opposite surfaces

$$
w=c_{p, \text { net }} \cdot q_{p}(z)
$$

where $c_{p, n e t}$ represent the resulting net pressure coefficients. The force coefficient and the net pressure coefficients (see in Fig. 1. and Tab.1) for free-standing canopy with inclination $27^{\circ}$ can be found in [1]. 

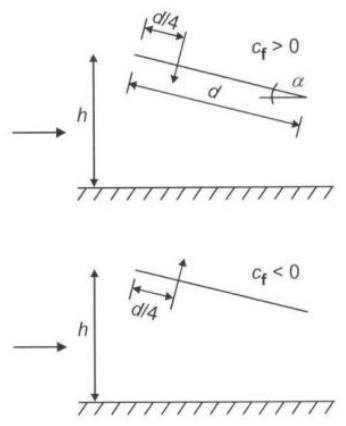
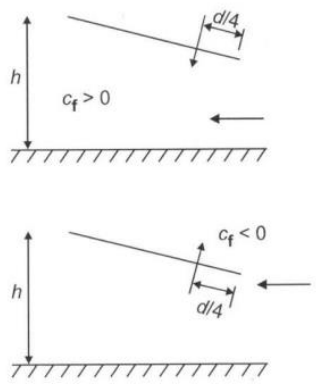

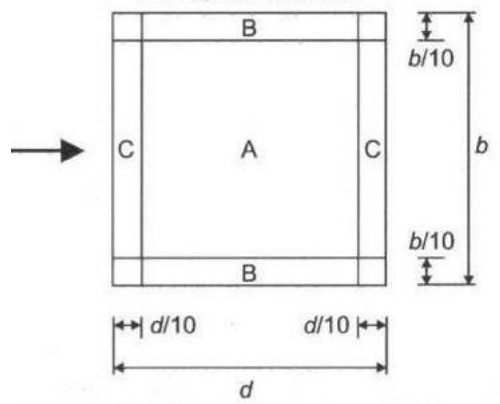

Fig. 1. Overall force and areas of net pressure coefficient for monopitch canopies [1].

Table 1. $c_{p, n e t}$ values for canopy.

\begin{tabular}{|c|c|c|c|}
\hline $\begin{array}{c}\text { Roof angle } \\
\boldsymbol{\alpha}\end{array}$ & Zone & $\begin{array}{c}\text { Downward } \\
\text { wind action }\end{array}$ & $\begin{array}{c}\text { Upward wind } \\
\text { action }\end{array}$ \\
\hline \multirow{3}{*}{$27^{\circ}$} & A & 2.08 & -2.76 \\
\cline { 2 - 4 } & B & 3.14 & -3.44 \\
\cline { 2 - 4 } & C & 2.34 & -3.36 \\
\hline
\end{tabular}

\section{Experimental investigation of the net pressure coefficient}

The solar panels can be arranged in different formations with gaps between them and therefore it is necessary to obtain experimentally the coefficients of the resulting wind pressure for individual areas and assuming all wind directions. The rear solar collectors are less stressed than in the front or on the side standing ones.

\subsection{Boundary layer wind tunnel and model of solar panels}

In the BLWT wind tunnel in Bratislava (see Fig. 2.), according to ACSE [4] we tested in the rear measuring space solar panel assemblies at different wind speeds and directions.

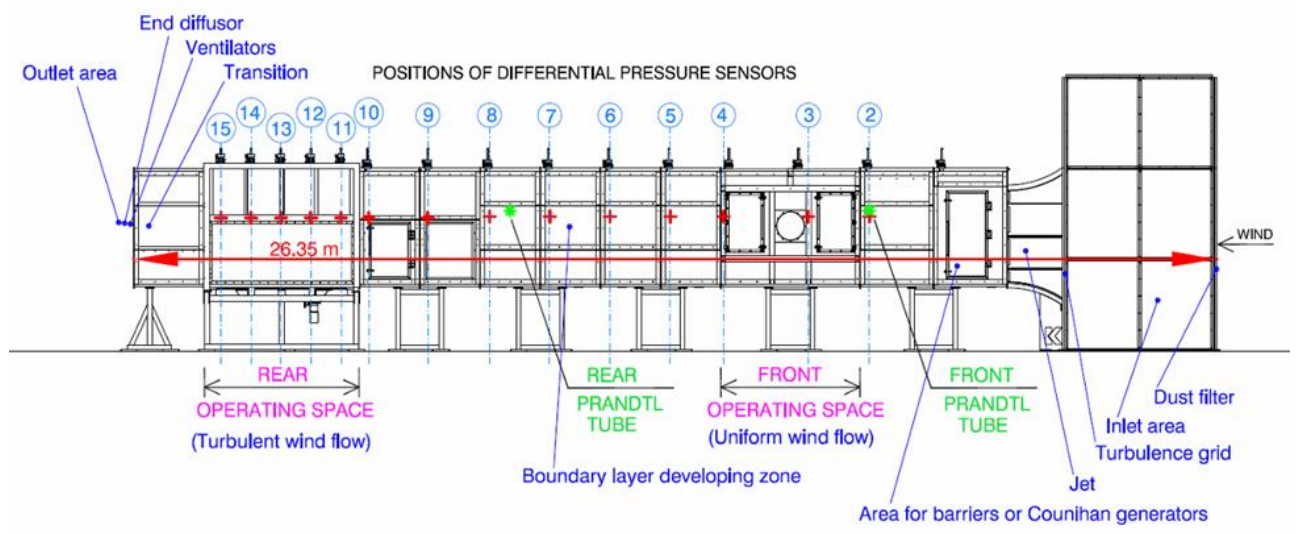

Fig. 2. BLWT wind tunnel scheme. 
The solar panel models in 1: 200 scale were placed behind the modeled and experimentally verified boundary layer of smooth terrain (terrain between I - II). The boundary layer representing the open terrain was modeled using smooth plates and a barrier. The flow velocities were set using LabVIEW, which controls the tunnel depending on the frequency of the inverters and had values of 24 and $28 \mathrm{~Hz}$, which corresponded to the mean values of the reference wind speeds at the top of the photovoltaic panel 6.965 and $8.15 \mathrm{~m} / \mathrm{s}$ depending on barometric pressure, temperature and air density.

External wind pressures corresponding to the reference speed at the top of the model were measured at two altitude levels along the panel. The total number of sampling points on one table was 43 . The location of the sampling points and the height levels were selected based on the results of CFD simulation. The layout of the sampling points on the panels and the view of the panel to be measured within the assembly are shown in Figs. 3, 4, 5.
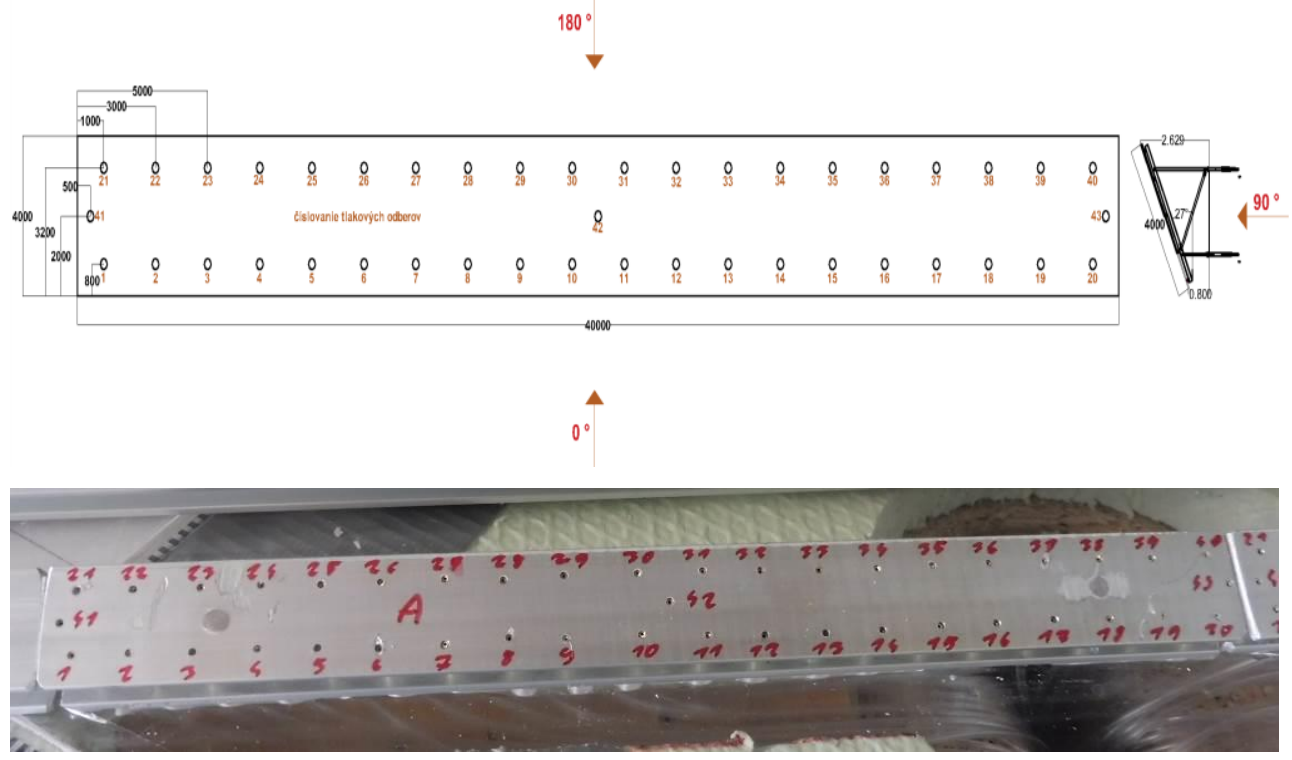

Fig. 3. Sampling points on the panel table and view of the model.

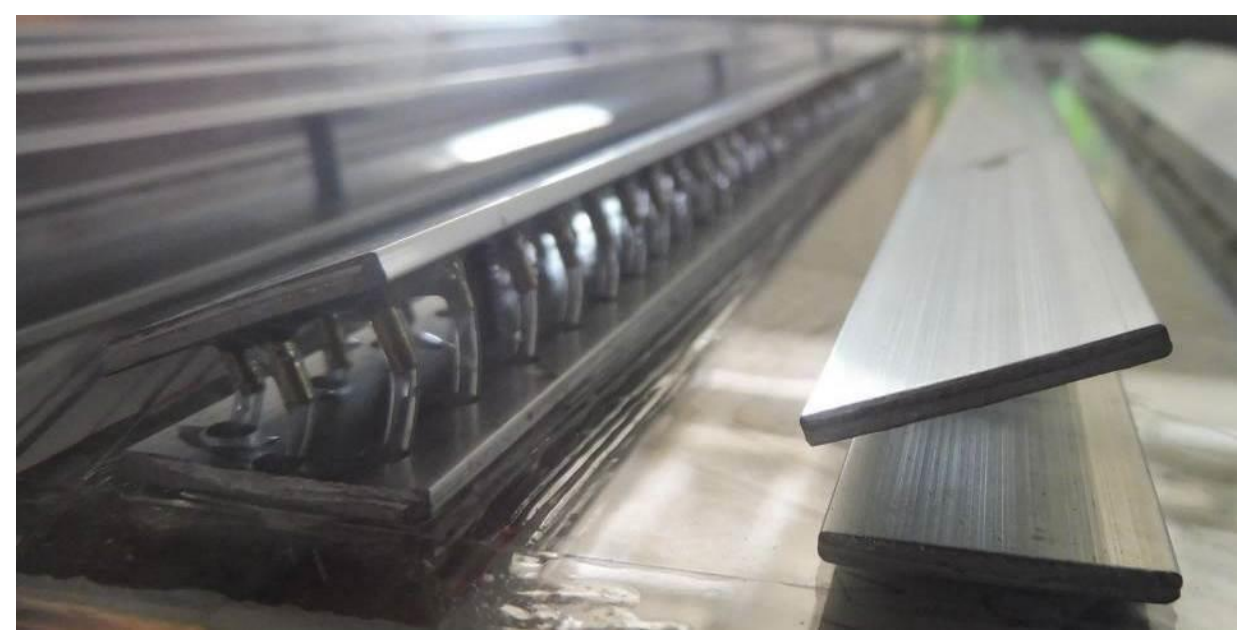

Fig. 4. Detail view of sampling points of pressure on panels. 
The triangular set consisted of 10 tables arranged in 4 rows, see Fig. 5. The models were placed on a turntable and rotated by $22.5^{\circ}$ to simulate a change of the wind direction acting on the object. The length of one table with panels was $40 \mathrm{~m}$ and width was $4 \mathrm{~m}$. The space between the tables was $0.3 \mathrm{~m}$ and the aisles between the tables were $4.536 \mathrm{~m}$.
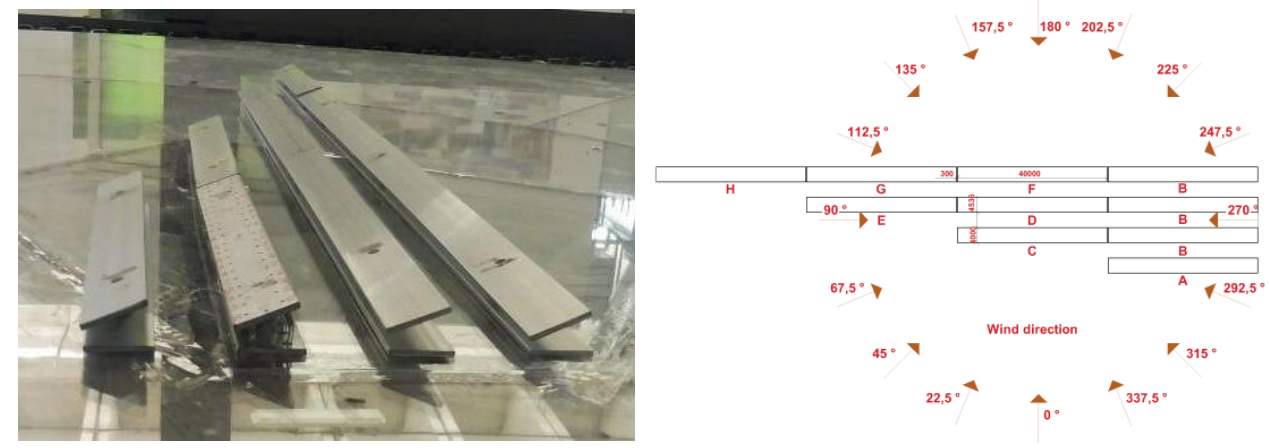

Fig. 5. Triangular panel layout on rotating table and measured wind directions.

\subsection{Evaluation of net pressure coefficients for photovoltaic panels}

The value of external wind pressure coefficient was calculated by Eq. 6

$$
c_{\mathrm{p}}=\frac{\Delta p}{p_{\mathrm{dyn}}\left(z_{\mathrm{ref}}\right)}=\frac{p(t)-p_{0}}{1 / 2 \cdot \rho \cdot \bar{v}^{2}\left(z_{\mathrm{ref}}\right)}
$$

where $p(t)$ is the wind pressure in measuring point on the surface of the model and $p_{0}$ is static pressure of undisturbed flow measured by Prandtl probe. Dynamic pressure of the mean wind velocity $p_{d y n}$ was considered in reference height (in our case, reference height was equaled to the height of the top of examined panel).

Wind pressure coefficients for the upper and lower table surfaces were obtained from the experiment. From these values the resulting net wind pressure coefficient $c_{p, n e t}$ was calculated as the difference between the values from the upper and lower table surfaces according to the relation

$$
c_{p, \text { net }}=c_{p, \text { upper }}-c_{p, \text { lower }}
$$

If the resulting pressure is negative, the table is loaded by suction, at a positive value it is the wind pressure. The evaluation of the results of the experimental measurements for the triangular assembly was plotted separately for the net pressure and net suction coefficients on the surfaces as the maximum of all wind directions [3, 5]. In view of the practical application of the values obtained for the net pressure coefficients, a conservative simplification is appropriate, similar to the EN 1991-1-4.

The resulting net pressure and suction wind coefficients that take into account all wind directions are shown in Figs. 6 and 7. The color range in the Figures shows significantly increased loads on the front and sides of the standing panels and less stress on the inner rows of the photovoltaic panels. 


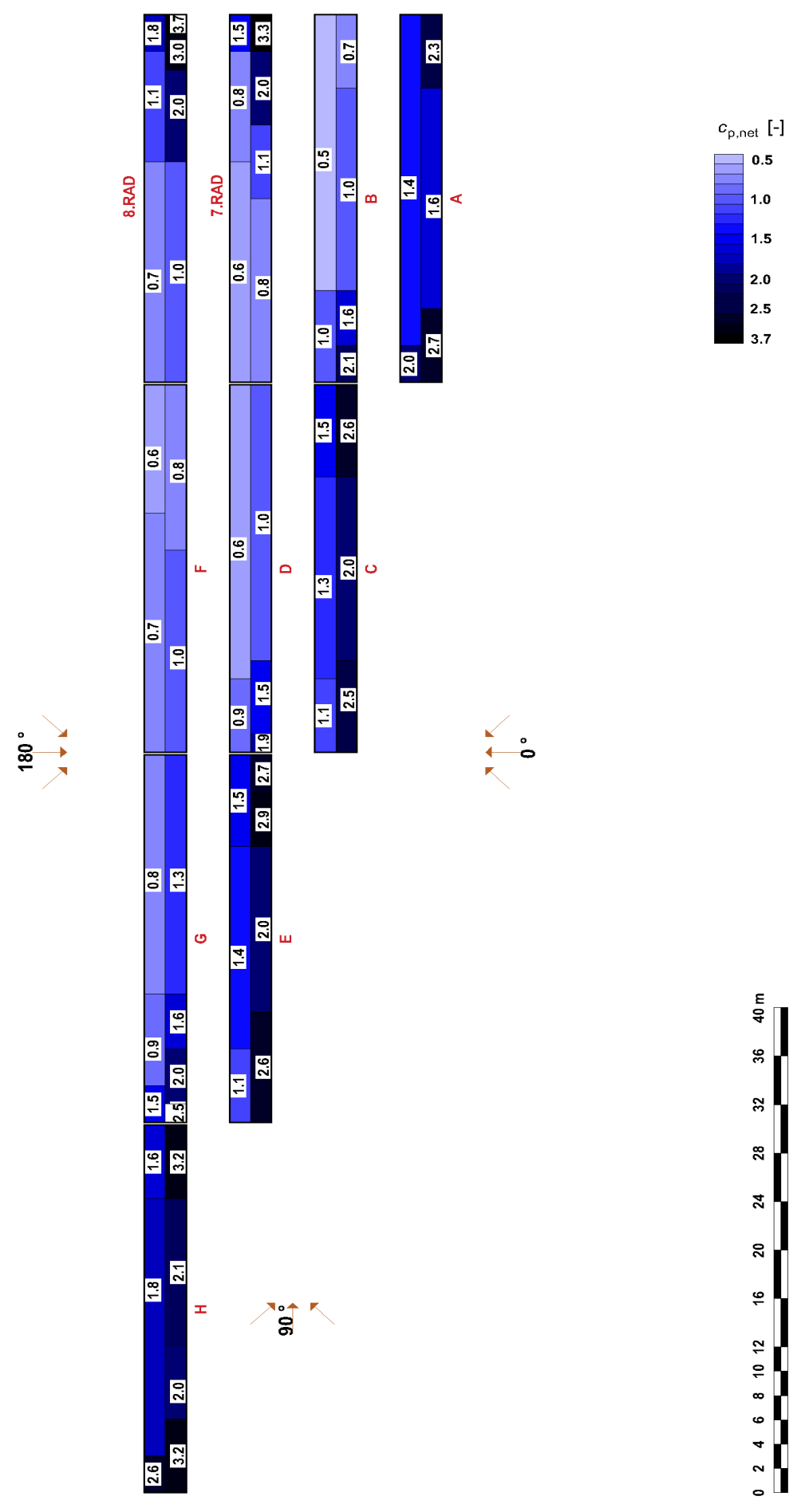

Fig. 6. Resulting net pressure coefficients for triangular assemblies of solar panels. 


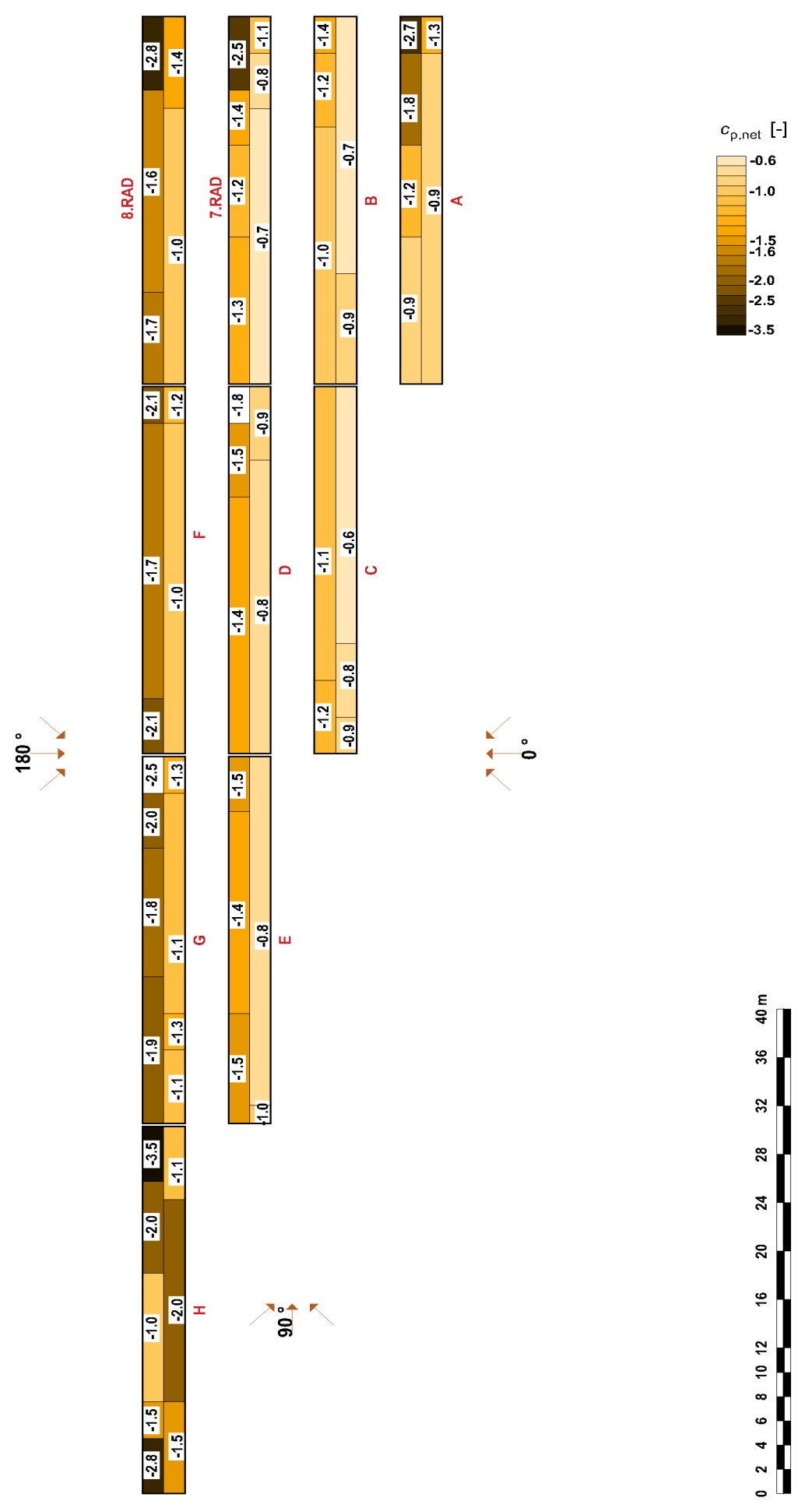

Fig. 7. Resulting net suction coefficients for triangular assemblies of solar panels. 
Table 2. Comparison of experimental $c_{p, n e t}$ values with open canopy roofs values.

\begin{tabular}{|c|c|c|c|c|c|}
\hline \multicolumn{2}{|c|}{ Net pressure coefficients for solar panels } & \multicolumn{3}{|c|}{ Net pressure coefficients for canopies } \\
\hline Zone & $\begin{array}{c}\text { Downward } \\
\text { wind action }\end{array}$ & $\begin{array}{c}\text { Upward wind } \\
\text { action }\end{array}$ & Zone & $\begin{array}{c}\text { Downward } \\
\text { wind action }\end{array}$ & $\begin{array}{c}\text { Upward wind } \\
\text { action }\end{array}$ \\
\hline Interior panels & 1.0 to 1.3 & -1.4 to -1.8 & A & 2.08 & -2.76 \\
\hline $\begin{array}{c}\text { Panels placed } \\
\text { on the side }\end{array}$ & $\mathbf{3 . 2}$ to $\mathbf{3 . 7}$ & -1.5 to $\mathbf{- 3 . 5}$ & B & 3.14 & -3.44 \\
\hline $\begin{array}{c}\text { Windward } \\
\text { front panels }\end{array}$ & 1.6 to 2.1 & -1.6 to -2.0 & C & 2.34 & -3.36 \\
\hline
\end{tabular}

\section{Conclusion}

The aim of the experimental research was to determine the coefficients of the resulting wind pressure on the solar panel system, since it is not possible to use the values from the standard in the triangular arrangement. The results are summarized in Table 2 and are compared with free standing open roofs. We can see that the inner panels are stressed considerably less than areas A for canopy roofs. The panels placed on the side of the assembly or on the edge of the aisle are stressed significantly more than parts B. Frontal panels are also less wind stressed than areas $\mathrm{C}$. The obtained values of wind effects on solar panels make it possible to optimize the design of the supports of the panel assembly and show the extremes of pressures and suction in the corners to be considered in the design.

Presented results have been arranged due to the research supported by the Slovak Scientific Grant Agency, projects VEGA No. 1/0412/18 and No. 1/0453/20.

\section{References}

1. EN 1991-1-4 Eurocode 1. Actions on structures. Part 1-4: General actions. Wind actions (2006)

2. O. Hubova, P. Lobotka, The Natural Simulations in the BLWT STU Wind Tunnel. ATF $3^{\text {rd }}$ Conference. E - Book, 78-84 (2014)

3. O. Hubova, Slovak Journal of Civil Engineering, XV, 3 (2007)

4. ASCE Manuals and Reports on Engineering Practice, no. 67, Wind Tunnel Studies of Buildings and Structures. Library of Congress Catalog Card No. 98-44103, USA (1999)

5. G. Solari, Gust buffeting. I: Peak wind velocity and equivalent pressure, J. Struct. Engng., ASCE, 119, 2, 365-382 (1993) 